\title{
Association between cavernous angioma and cerebral glioma. Report of two cases and literature review of so-called angiogliomas
}

\author{
R. Gazzeri; C. De Bonis*; V. Carotenuto*; D. Catapano*; V. d'Angelo* y M. Galarza**
}

Department of Neurosurgery. San Giovanni-Addolorata Hospital. Rome. Italy. Department of Neurosurgery*. IRCCS "Casa Sollievo della Sofferenza". San Giovanni Rotondo. Italy. Department of Neurosurgery**. University Hospital Virgen de la Arrixaca. Murcia. Spain.

\section{Summary}

The association between vascular malformations and cerebral gliomas is unusual. While the association between cavernous angioma with gliomatous lesions is even more rare, it is considered by certain authors to be a particular pathological entity termed angioglioma. The authors report on two cases of association of a cavernous angioma with a ganglioglioma and an oligodendroglioma respectively. Subsequent review of the literature on the so-called angiogliomas was conducted. In the author's opinion, the entity of angiogliomas represents a general spectrum of angiomatous neoplasms that include gliomatous tumors, in the majority low-grade gliomas, associated with a major vascular component.

KEY WORDS. Brain tumor. Glioma. Cavernous angioma. Angioglioma

Asociación entre angioma cavernoso y glioma cerebral. Reporte de dos casos y revisión de la literatura acerca de los llamados angiogliomas

\section{Resumen}

La asociación entre las malformaciones vasculares y los gliomas cerebrales es inusual. Mientras que la asociación entre angioma cavernoso con lesiones gliomatosas es aún más rara, es por esto considerado por algunos autores como una entidad patológica particular llamada angioglioma.

Los autores reportan dos casos de asociación de un angioma cavernoso con una ganglioglioma y un oligodendroglioma, respectivamente. Además se realizó una revisión de la literatura sobre los llamados angiogliomas.

En opinión de los autores, la entidad de los angiogliomas se presenta dentro de un espectro general de neoplasias angiomatosas, que incluyen tumores cerebrales, en su mayoría gliomas de bajo grado, asociados a su vez, con un componente vascular importante.

Recibido: 5-12-10. Aceptado: 17-02-11
PALABRAS CLAVE. Tumor cerebral. Glioma. Angioma cavernoso. Angioglioma.

Introduction

Councillmann in $1930^{3}$ was the first to report the name of "angiogliomas" describing a cerebellar tumor with a huge vascular component. From Councillmann until nowadays, only a few authors have reported this entity along with an attempt of a better definition of such pathology.

Indeed, Roussoy and Oberling in $1930^{14}$ classified CNS neoplams and described as well the angioglioma that it was defined as a tumor with a glial part, generally of low-grade, along with a notable vascular component. Although, Rubinstein ${ }^{15}$ accepted the term angioglioma; in a more recent publication ${ }^{16}$ he suggested the restriction of the term angiogliomas to denote a mixed tumor composed of an hemangioblastoma and astrocitoma. Sugita et al. ${ }^{9}$, after reporting a case of a xanthoastrocitoma highly vascularized, proposed the use of the term angiomatous glioma intending to describe a malignant glial neoplasms highly vascularized, while leaving the term angiogliomas just for mixed neoplasms composed of a lowgrade glioma and a vascular malformation of any kind.

The presence of two angiogliomas in our own series of low-grade gliomas leaded us to review the literature on this rare pathological condition ${ }^{2,3,8,12,13,14}$.

\section{Case 1}

A 16-year-old girl was admitted in our department for progressive bilateral facial palsy. Neurological examination evidenced a central bilateral VII cranial nerve dysfunction. A brain MRI with and without contrast demonstrated a hypothalamic chiasmatic tumor with disomogenous contrast enhancement, irregular borders and slight perilesional edema (Fig1). A bilateral subfrontal approach was carried out with subtotal resection of the tumor. During surgery, an intracerebral mass with thrombosed vessels and considerable vascular lakes was found. Histological diagnosis was ganglioglioma with glial component of pyloid type and associated vascular component of angiomatous type (angio- 


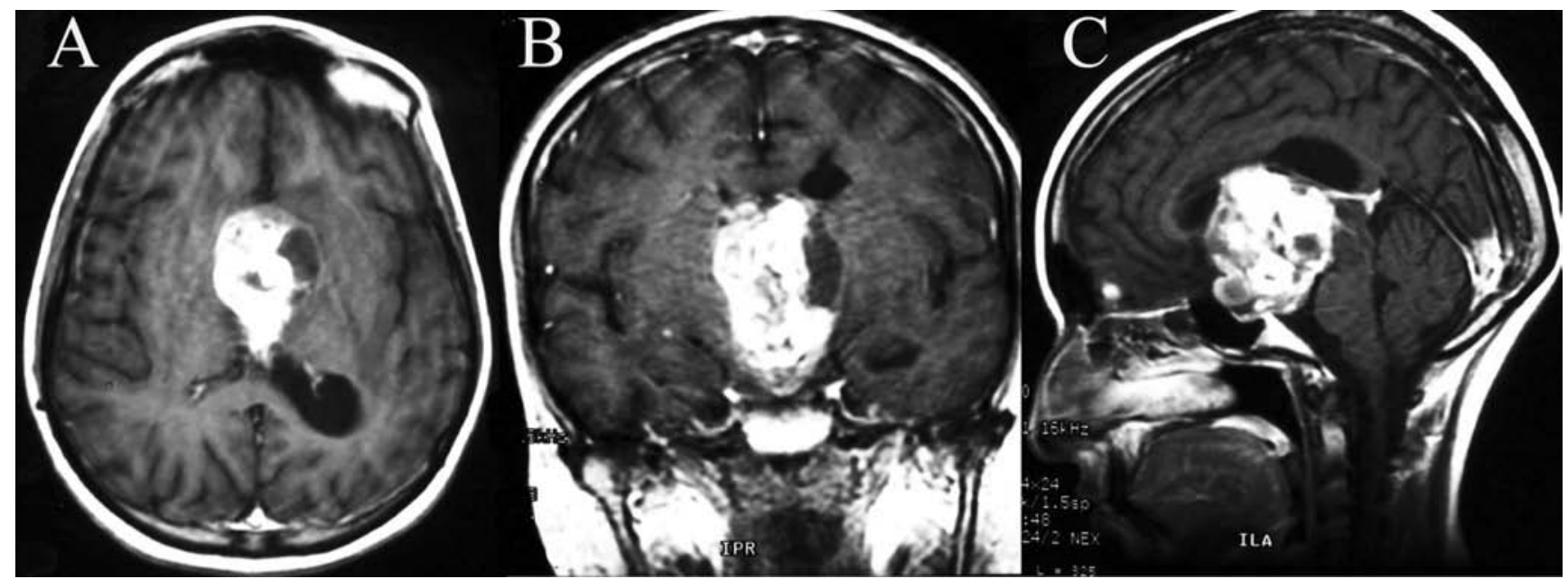

Figure 1. Brain MR T1-weighted axial (a), coronal (b) and sagittal (c) images showing a hypothalamic-chiasmatic tumor with disomogenous contrast enhancement, irregular borders and slight perilesional edema.

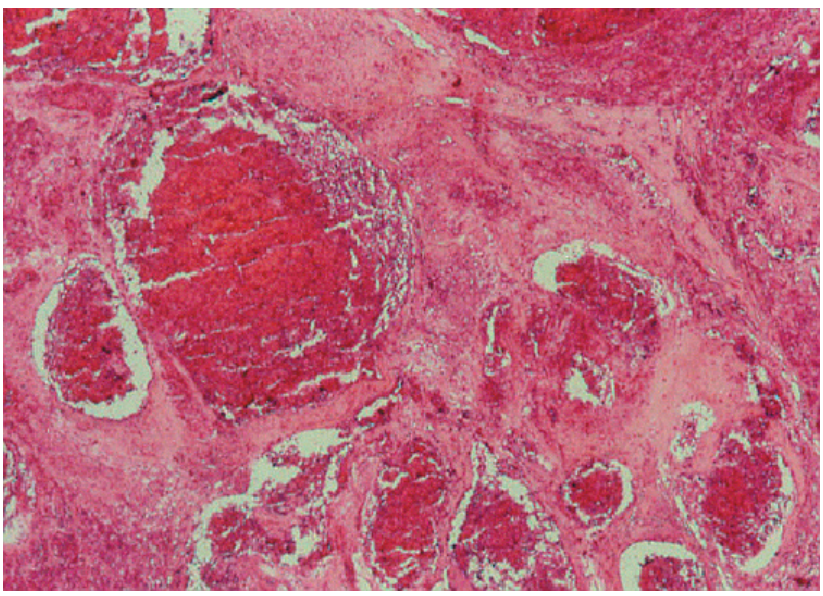

Figure 2a. Vascular component of neoplasia (evident angiomatous aspect). H\&E. Original magnification 200x.

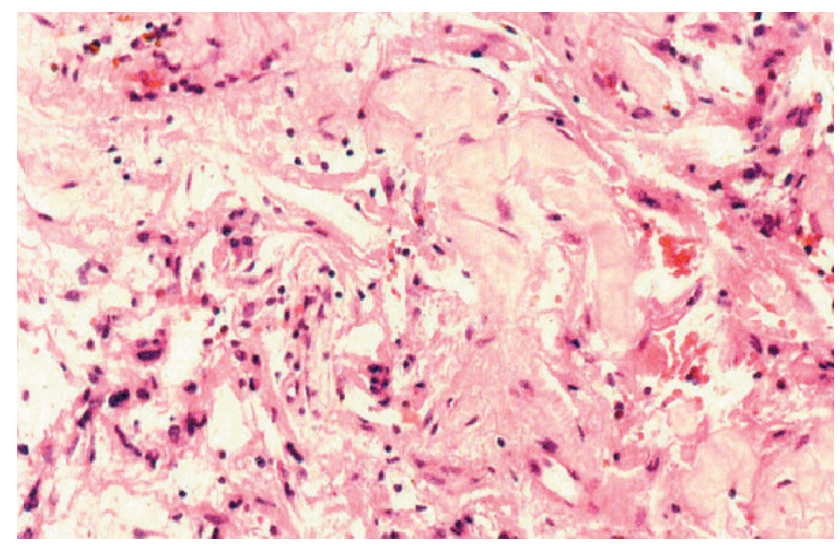

Figure $2 \mathrm{~b}$. Interface between vascular component (in this case with hyalinized ectasic walls) and the glial neoplasia. $H \&$ E. Original magnification 100x.

glioma). The vascular component was observed in some regions of the tumoral mass. It presented itself with hya-

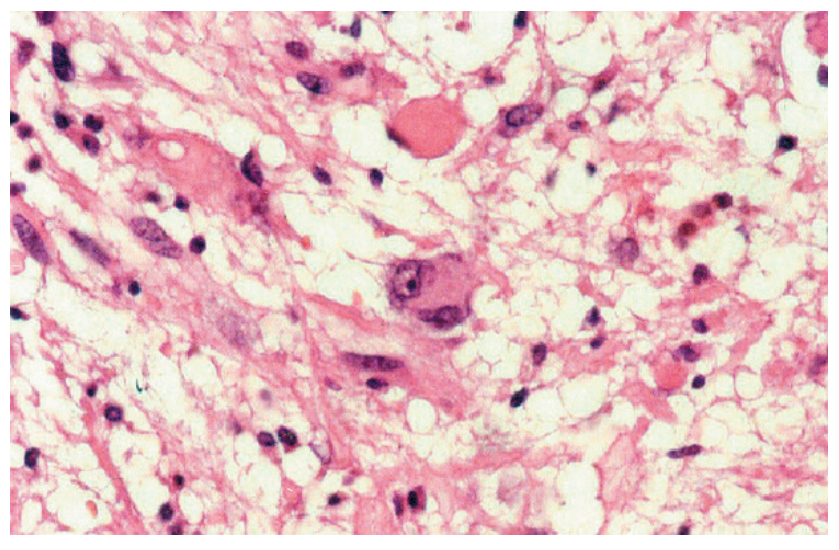

Figure 2c. Particular of the ganglioglial component (one binuclear gangliar cell in the center). H\&E. Original magnification 200x.

linized ectasic vascular channels, perivascular hemosiderin deposits, gliosis and vascular calcifications. The gliomatous nature of the tumor was pathologically obvious, although in some points of the tumoral mass it was nearly darkened from this particular architecture of the vascular component (Fig 2a, b, c). Electron microscopy was not performed.

Postoperative course was complicated with a panhypopituitarism, which improved with pharmacological replacement therapy. Clinical and radiological follow-up of 76 months showed a non growing residual tumor and stable medical condition.

\section{Case 2}

A 38-year-old men was admitted in our department for bifrontal headaches for six months. Neurological exam was normal. A brain MRI with and without contrast demonstrated a right frontal lobe tumor with disomoge- 


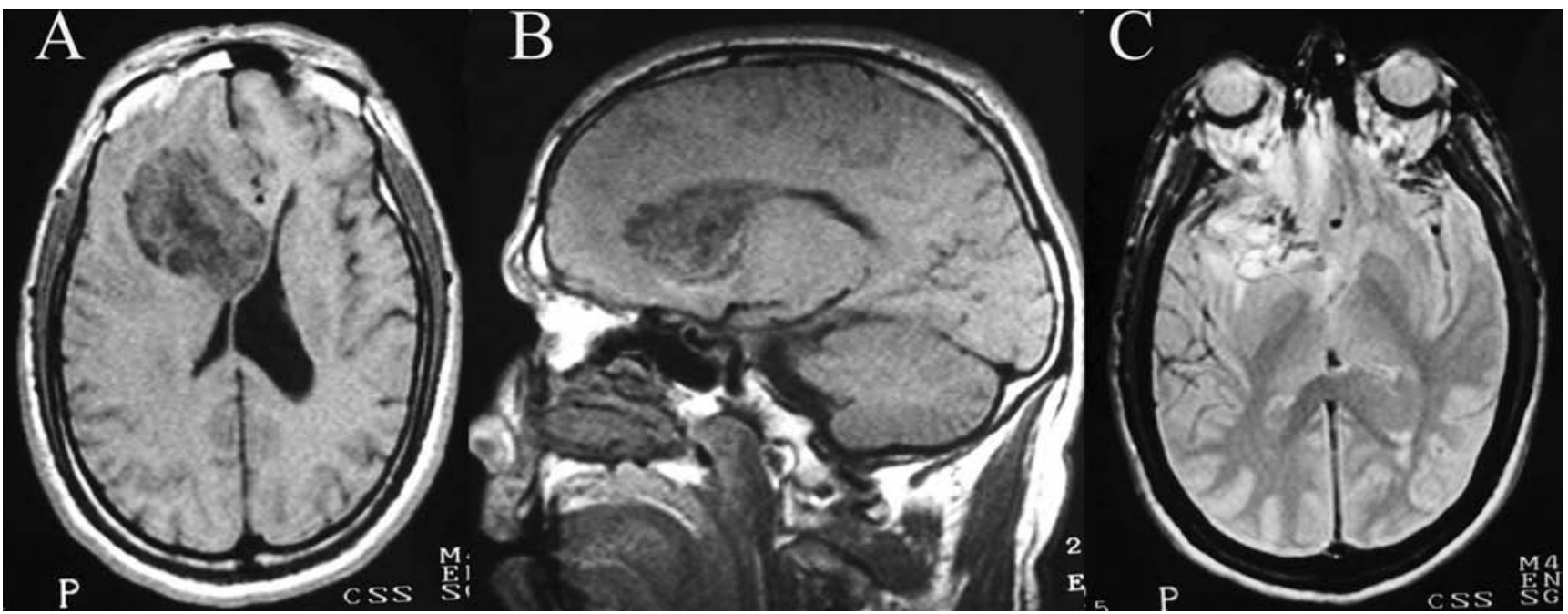

Figure 3. Brain magnetic resonance T1-weighted axial (a) and sagittal (b) images showing a right frontal lobe tumor with disomogenous intensity. (c)Axial T2-weighted image showing the vascular component of the tumor.

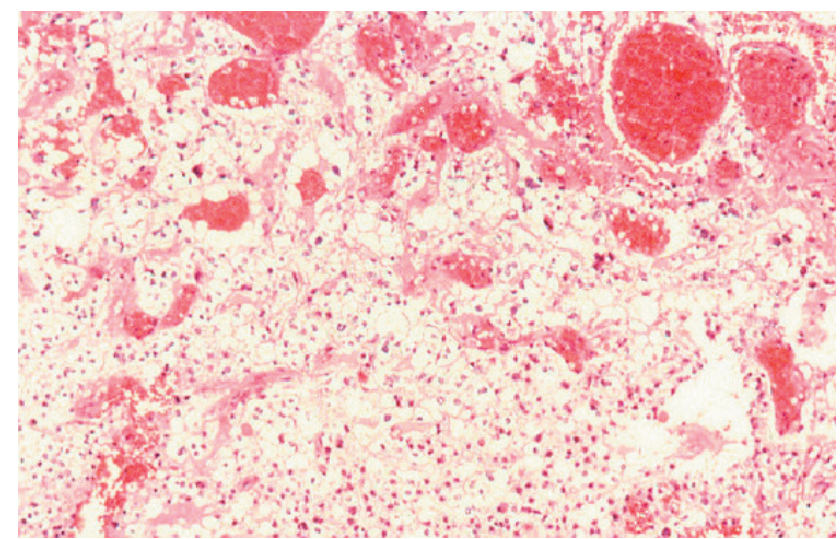

Figure 4a. Interface between vascular and glial component. H\&E. Original magnification 100x.

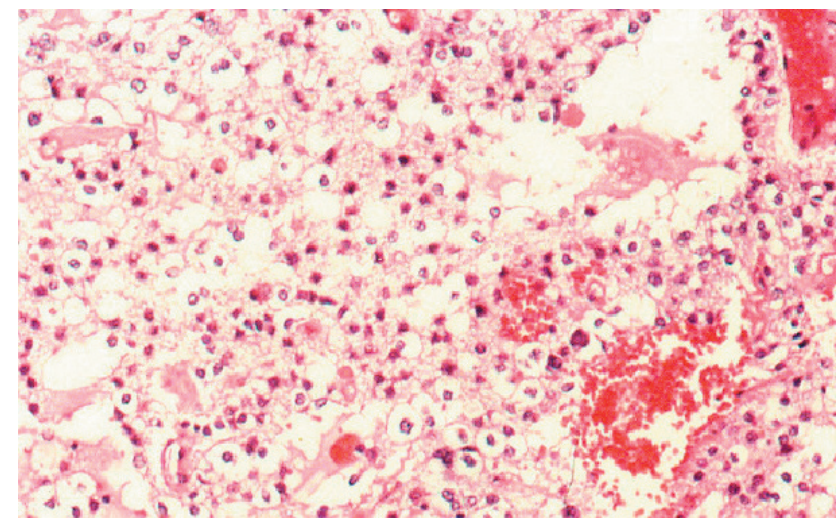

Figure 4b. Particular of the glial component of type oligodendroglioma with polymorphous aspects. H\&E. Original magnification $100 x$.

nous contrast enhancement and areas of hyperintensity surrounded by a hypointense ring due to the paramagnetic effects of hemosiderin (Fig. 3). A right frontal craniotomy was performed with a total removal of the tumor. Histological diagnosis was angioglioma with a glial component of oligodendroglioma with polymorphous aspects; a prominent vascular component was observed in some regions of the tumoral mass. Hyalinized ecstatic vascular channels, perivascular hemosiderin deposits, gliosis and vascular calcification were noted (Fig. 4a, b). Postoperative evolution was uneventful. Clinical and radiological follow-up of 64 months showed a neurologically intact patient without tumoral recurrence on imaging studies.

\section{Discussion}

From a consecutive series of 168 low-grade gliomas surgically treated in our department from 1992 to 2003, we found 2 cases with histological diagnosis of "Cerebral Angioglioma". After revision of these two cases it was evidenced that the vascular part assumed a cavernous-angioma like component, while the gliomatous part were a pyloid type ganglioglioma in one case and an oligodendroglioma in other case. In 1991 Lombardi et al. ${ }^{10}$ reviewed the histological diagnosis of a series of 1034 surgically treated MAV, and concluded that the entity of the angioglioma belonged to a distinct and rare pathological category composed of a lowgrade glial neoplasm with a rich vascular part, with same clinical and angiographic characteristics, along with prognosis, of those gliomas without an angioma-like vascular component. Palma et al. ${ }^{13}$ described other two cases with verified association between glioma and cavernous angioma, that were defined as examples of angiogliomas.

Some authors ${ }^{1,5,6,11,20,21}$ expressed different etiological hypothesis including: genetical predisposition ${ }^{20}$; reactive or malformative nature ${ }^{1,6,21}$; viral origin ${ }^{5}$; and exceptional 
coincidence ${ }^{7,9}$. White et $\mathrm{al}^{20}$, sustained the hypothesis of a genetical predisposition of these mixed tumors after reporting the autopsy of a 45 year-old male patient with cerebral, lung and hepatic cavernomas deceased after surgery for a septum pellucidum astrocytoma.

Crowel $^{4}$, Nazek ${ }^{12}$ and Lombardi ${ }^{10}$, suggested that an exaggerated glial proliferation could be a reactive response to any kind of AVM, with subsequent chronic ischemia and white matter changes.

Fisher in $1982^{5}$, reporting two cases of cavernous angioma associated with an oligodendroglioma and a pylocitic astrocytoma respectively, considered a viral cause as a possible pathogenesis. Indeed, cavernomas can be induced experimentally in rats after inoculation of Polyoma virus, while the neoplasm can be induced directly after inoculation of SV40 virus of the Papova family.

Nazek et al. ${ }^{12}$ reported 3 cases of AVM association with abnormal oligodendroglial proliferation, and Spetzler ${ }^{18}$ cited a personal case of association between an AVM and an oligodendroglioma, affirming the existence of a rare coincidence between AVM and gliomas. In our first case the histological diagnosis was ganglioglioma with glial component of pyloid type and associated vascular component of angiomatous type, while in our second case histological examination showed a glial component of oligodendroglioma with polymorphous aspects; in both cases the vascular component was observed in some regions of the tumoral mass.

We can include cases of angiogliomas either as an exclusive pathological entity, or as a unique category of angiogliomatous tumors composed of a low-grade glioma associated with an important vascular component. However, after reviewing the literature and our cases, the following subcategories can be described:

-Hypervascularized low-grade gliomas.

-Mixed gliomas, with an angiomatous and a glial component, both components secondary to oncogenic factors.

-Serendipity of an AVM with a glioma in two adjacent contiguous regions.

-Coincidence of an AVM with a glioma in two distant regions cannot be considered within angiogliomas and this entity should be considered as coexistence of two different pathologies.

-The exuberant glial proliferation that is seen in cases of AVM regions cannot be considered within angiogliomas, because it seems to be secondary to tissue changes after chronic ischemia and gliosis. These cases did not demonstrated progression to glial neoplasm and have a natural history similar to other AVMs.

-Prognosis of angiogliomatous tumors depends on different factors: a) intrinsic biological behavior, malignancy and tumoral grading; b) tumoral location; c) ame- nability and extent of resection; d) adjuvant therapies. In our first case follow-up of 76 months showed a nongrowing residual tumor and stable medical condition; in the second case, follow-up of 64 months showed a neurologically intact patient without tumoral recurrence on MR images.

\section{Conclusions}

Based on our experience and on the literature review, we imply that the presence of rare cases of any kind of AVM associated with a glioma can be interpreted as a truly compound tumor, less likely to be an exceptional coincidence. We suggest that the entity of angiogliomas represents a general spectrum of angiomatous neoplasms that include gliomatous tumors, in the majority low-grade gliomas, associated with a major vascular component.

\section{References}

1. Bonnin, J.M., Pena, C.E., Rubinstein, L.J.: Mixed capillary hemangioblastoma and glioma. A redefination of the "angioglioma". Neuropathol Exp Neurol 1983; 42: 504-516.

2. Chee, C.P., Johnston. R., Doyle, D., McPherson, P. Oligondendroglioma and cerebral cavernous angioma. Case report. J Neurosurg 1985; 62: 145-147.

3. Councilman, W.T.: The gliomatous tumors of the brain. Long Island Med J 1914; 8: 401-409,

4. Crowell, R.M., De Girolami, U., Sweet, W.H.: Arteriovenous malformation and oligodendroglioma. Case report. J Neurosurg 1975; 43: 108-111.

5. Fisher, E.G., Sotrel, A., Welch, K.: Cerebral hemangioma with glial neoplasia (angioglioma?) Report of two cases. J Neurosurg 1982; 56: 430-434.

6. Goodkin, R., Zaias, B., Michelsen, W.J.: Arteriovenous malformation and glioma: coexistent or sequential? J Neurosurg 1990; 72: 798-805.

7. Heffneer, R.R., Porro, R.S., Deck, M.D.F.: Benign astrocytoma with arteriovenous malformation. Case report. J Neurosurg 1971; 35: 229-233.

8, Kasantikul, V., Netsky, M.G.: Combined neurilloma and angioma. Tumor ectomesenchyme and a source of bleeding. J Neurosurg 1979; 50: 81-87.

9. Licata, C., Pasqualin, A., Freschinie, A., Barone, G., DaPian, R.: Management of associated primari cerebral neoplasms and vascular malformations. Acta Neurochir (Wien) 1986; 83: 38-46.

10. Lombardi, D., Scheithauer, B.W., Piepgras, D., Meyer, F.B., Forbes, G.S. "Angioglioma" and the arteriovenous malformation-glioma association. J Neurosurg 1991;75: 589-596.

11. Mc Cormick, W.F., Hardman, J.M., Boulter, T.R.: Vascular malformations ("angiogliomas") of the brain, with special reference to those occurring in the posterior fossa. $\mathrm{J}$ 
Neurosurg 1968; 28: 241-251.

12. Nazek, M., Mandybur, T.I., Kashiwagi, S.: Oligodendroglial proliferativeabnormality associated with arteriovenous malformation: report of three cases with review of the literature. Neurosurgery 1988; 23: 781-785.

13. Palma, L., Mastronardi, L., Celli, P., d'Addetta, R.: Cavernous Angioma associated with Oligo- Astrocytoma-like proliferation: report of two cases and review of the literature with a reappraisal of the term "Angioglioma". Acta Neurochir 1995; 133: 169-173.

14. Roussy, G., Oberling, C.: Les tumeurs angiomateuses des centre nerveux. Presse Med 1930; 38: 179-185.

15. Rubinstein, L.J.: Tumors of the Central Nervous System. Atlas of Tumor Pathology. Series 2, Fascicle 6. Washington, DC: Armed Forces Institute of Pathology, 1972.

16. Russel, D.S., Rubinstein, L.J.: Pathology of Tumours of the Nervous System, ed 5. Baltimore: Williams \& Wilkins, 1989.

17. Shah, D., Naheed, M.H., O'Hara, R.: Intracranial vascular malformation and astrocytoma. IMJ 1985; 169: 388390.

18. Spetzler, R.F.: Comment to Nazek. Neurosurgery 1988; 23: 781-785.

19. Sugita, Y., Kepes, J.J., Shigemori, M., Kuramoto, S.,
Reifenberger, G., Kiwit, J.C., Wechsler, W.: Pleomorphic Xantoastrocytoma with desmoplastic reaction: angiomatous variant. Report of two cases. Clin Neuropathol 1990; 9: 271278.

20. White, R.J., Jernohan, J.W., Wood, M.W.: A study of fifty intracranial vascular tumors found accidentally at necropsy. J Neuropathol Exp Neurol 1958; 17: 392-398.

21. Zuccarello, M., Giordano, R., Scanarini, M., Mingrino, S.: Malignant astrocytoma associated with arteriovenous malformation. Case report. Acta Neurochir (Wien) 1979; 50: 305-309.

22. Zulch, K.J.: Histological typing of tumours of the Central Nervous System. Geneva: World Health Organization, 1979.

Gazzeri, R.; De Bonis, C.; Carotenuto, V.; Catapano, D.; d'Angelo, V.; Galarza, M.: Association between cavernous angioma and cerebral glioma. Report of two cases and literature review of so-called angiogliomas. Neurocirugía 2011; 22: 562-566.

Correspondence. Marcelo Galarza, M.D., M.Sc. Department of Neurosurgery. Hospital Universitario Virgen de la Arrixaca, C/ Cartagena s/n. El Palmar, Murcia, 30120, Spain

Email: marcelo.galarza@carm.es 